\title{
Postnatal evolution of slow variability in cerebral blood flow velocity
}

\author{
Heather Coughtrey, Janet M Rennie, David H Evans
}

\begin{abstract}
The evolution of low frequency variability in cerebral blood flow velocity (CBFV) was examined in 30 consecutive admissions of very low birthweight babies. Measurement of CBFV was made on the first day of life and at weekly intervals until discharge. Altogether 133 recordings were subjected to visual classification and described as showing presence or absence of variability at a frequency between 1 and 5/minute. Amplitude of variability was expressed as the largest variation in peak systolic velocity as a percentage of the maximum systolic change.

Slow variability was usually obvious and was sometimes present for only part of the minute recorded. There was a significant trend for decreased incidence of slow variability in relation to both postconceptional and postnatal ages. Amplitude of slow variability was also damped with increasing age.

Slow variability appeared to be unrelated to the type of sedation, severity of illness, or intracranial pathology; it may be a normal phenomenon in which damping occurs as the autonomic nervous system matures.
\end{abstract}

Small variations in heart rate and blood pressure have been recognised since the nineteenth century. Traube ${ }^{1}$ and Hering ${ }^{2}$ described fluctuations in blood pressure at the same frequency as respiration. Mayer described waves in blood pressure slower than those of respiration in animals with spontaneous respiratory movements. ${ }^{3}$ Guyton and Harris reported cycles of blood pressure at a frequency of 1 to $5 /$ minute in deteriorating animal preparations. ${ }^{4}$ Recently, Anthony et al have described slow variability of cerebral blood flow velocity (CBFV) in both term and preterm newborn babies at a similar frequency. 5 In short term recordings a highly variable CBFV has been implicated in the aetiology of intracranial pathology in the very low birthweight infant. ${ }^{6}$ Slow variability is important because in a recording of CBFV lasting only part of one minute its presence might lead to misinterpretation of beat to beat variability.

In adults ${ }^{78}$ and term newborn infants, ${ }^{9}$ slow variability is thought to be influenced by both thermoregulation and by baroreceptor reflex control mediated by the autonomic nervous system, and this may also be true for the preterm infant. ${ }^{10}$ Studies recording CBFV in adults over 30 minute periods do not report the presence of slow variablity, ${ }^{11}$ suggesting that at some point of postconceptional age this becomes so damped as to be undetectable.
In this study we examined slow variability in CBFV in preterm infants in a longitudinal study extending to 14 weeks of postnatal age.

\section{Patients and methods}

PATIENTS

The study was carried out in the Special Care Baby Unit (SCBU) at the Rosie Maternity Hospital in Cambridge between December 1989 and October 1990. From a cohort of 74 consecutive admissions of babies with birth weight $<1500 \mathrm{~g}, 30$ remained longer than four weeks and were the subjects of this study. Infants were excluded only if they had a lethal congenital malformation, were admitted to the SCBU after 24 hours of age, or were less than the third centile for weight for gestational age. Informed consent was obtained from one or both parents. The study was approved by the district ethics committee.

\section{METHODS}

Recordings of CBFV were made using Duplex Doppler ultrasound (ATL Mk600) on day one and at weekly intervals thereafter until discharge. These were performed by a single operator. Doppler signals were processed using a microcomputer based system developed by Schlindwein and Evans. ${ }^{12}$ This used a fast Fourier transform to calculate the peak velocity every $6.25 \mathrm{~ms}$ and passed the result to a second microcomputer (Apple Macintosh II running Labview) which was used to store the data. Each recording lasted one minute. Subsequently the velocity recording was visually inspected, and classified as showing variability at a frequency of between 1 and 5/minute, showing no such variability, or as unclassifiable. Variability at frequencies above $5 /$ minute, probably due to the influence of respiration, was not considered in this study.

Amplitude of variability was then calculated by using the maximum systolic velocity present in the whole recording, subtracting the minimum systolic velocity, and dividing by the maximum systolic velocity. This was then expressed as a percentage.

We validated the visual classification of slow variability by comparing visual inspection with calculated values of maximum variability. A value of less than $10 \%$ maximum variability was used as a cut off for comparison with visual classification of no slow variability, as previous work has shown that short term variability is usually less than $10 \% .^{13}$

Each week study babies also had standard 
views of cerebral ultrasound recorded by skilled independent operators who assessed them for periventricular haemorrhage and for ischaemic lesions (periventricular leucomalacia).

\section{Results}

Altogether 133 recordings were obtained from 30 babies of mean birth weight $1113 \mathrm{~g}$ (range 573-1486) and mean gestational age 27 weeks (range 24-31). Postnatal age extended from birth to a maximum of 14 weeks. Babies ranged from those never ventilated to those ventilated for more than 28 days (table 1 ).

Six infants suffered a periventricular haemorrange of a grade greater than 2 (three grade 4, and three grade 3 according to the classification of Levene et $a l) .{ }^{14}$ Four infants had ischaemic lesions, one with huge multifocal cysts, two with single anterior cysts, and one with multiple anterior cysts. One required shunting for posthaemorrhagic hydrocephalus. Slow variability was usually obvious, with only four recordings out of the 133 being unclassifiable. There was good agreement between visual classification and calculated amplitude of less than $10 \%$ (table 2).

Slow variability was sometimes present for only part of the minute recorded. When more than one cycle was observed, the cycle length was not always the same, meaning that the variability was not occurring at a constant frequency. The occurrence of slow variability decreased with increasing postconceptional age. All babies showed slow variability up to 26 weeks' postconceptional age, whereas this was observed in only $70 \%$ at 32 weeks and at 37 weeks this had fallen to $25 \%$ (fig 1 ). The $95 \%$ confidence intervals for this trend showed a significant reduction with increasing postconceptional age, as seen in fig $2 \mathrm{~A}$; babies were divided into four groups of increasing post-

Table 1 Characteristics of study infants $(n=30)$

\begin{tabular}{llll}
\hline & Mean & Range & $\begin{array}{l}\text { No of } \\
\text { infants }\end{array}$ \\
\hline Birth weight (g) & 1113 & $573-1486$ & \\
Gestational age (weeks) & $27 \cdot 7$ & $24-31$ & \\
$\begin{array}{l}\text { No of days ventilated } \\
\text { No of days in oxygen }\end{array}$ & $9 \cdot 3$ & $0 \cdot 5-44$ & \\
$\begin{array}{l}\text { Periventricular haemorrhage: } \\
\quad \text { Grade 3 }\end{array}$ & $1-200$ & \\
$\quad \begin{array}{l}\text { Grade 4 } \\
\text { Periventricular leucomalacia }\end{array}$ & & 4 \\
\hline
\end{tabular}

Table 2 Comparison of visual inspection compared with measured amplitude of slow variation

\begin{tabular}{|c|c|c|c|}
\hline & \multicolumn{3}{|c|}{$\begin{array}{l}\text { Validity of visual } \\
\text { classification }\end{array}$} \\
\hline & $\begin{array}{c}\text { Slow variability } \\
\text { present }\end{array}$ & Slow & $\begin{array}{l}\text { variability } \\
\text { bsent }\end{array}$ \\
\hline $\begin{array}{l}\text { Maximum change in } \\
\text { systemic velocity } \\
<10 \%\end{array}$ & $\begin{array}{c}3 \\
\text { (false positive) }\end{array}$ & (true & $\begin{array}{l}54 \\
\text { positive) }\end{array}$ \\
\hline \multirow[t]{2}{*}{$\begin{array}{l}\text { Maximum change in } \\
\text { systemic velocity } \\
>10 \%\end{array}$} & $\begin{array}{c}157 \\
\text { (true negative) }\end{array}$ & (false & $\begin{array}{l}11 \\
\text { negative) }\end{array}$ \\
\hline & $\begin{array}{l}\text { Positive predictive } \\
\text { Negative predictive } \\
\text { Efficiency } \\
\text { False positive } \\
\text { False negative }\end{array}$ & $\begin{array}{l}\text { alue } \\
\text { value }\end{array}$ & $\begin{array}{r}94 \cdot 7 \% \\
93 \cdot 5 \% \\
93 \cdot 8 \% \\
1 \cdot 9 \% \\
19 \cdot 3 \%\end{array}$ \\
\hline
\end{tabular}

conceptional age. Each group contained approximately equal numbers of babies.

A similar trend was seen with respect to postnatal age; the proportion showing epochs of no slow variability increased with increasing postnatal age. When $95 \%$ confidence intervals were calculated there was a significant difference between groups 1 and 3 and between groups 2 and 4 (fig 2B). In this instance groups consisted of babies of increasing postnatal age divided into periods of four weeks.

There was also a significant trend for damping of the amplitude of slow variability with increasing postconceptional age and with increasing postnatal age. Regression analyses of decreasing amplitude of variability with increasing age showed a significant correlation coefficient for seven of the eight babies with more

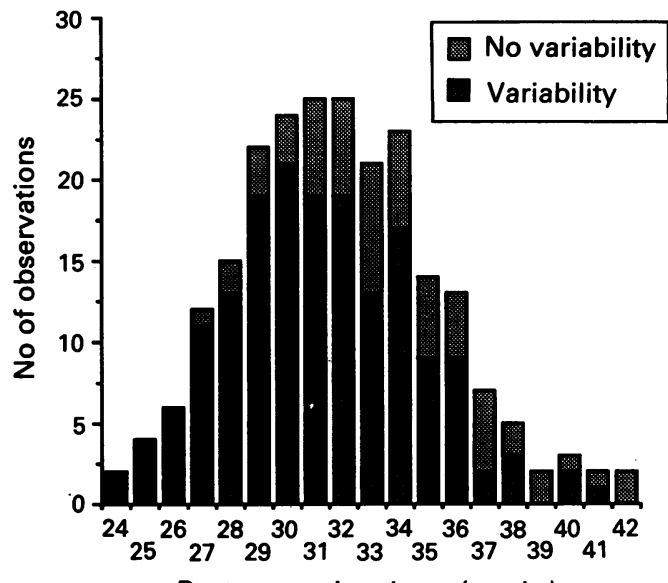

Postconceptional age (weeks)

Figure 1 Presence of slow variability in $C B F V$ related to postconceptional age.

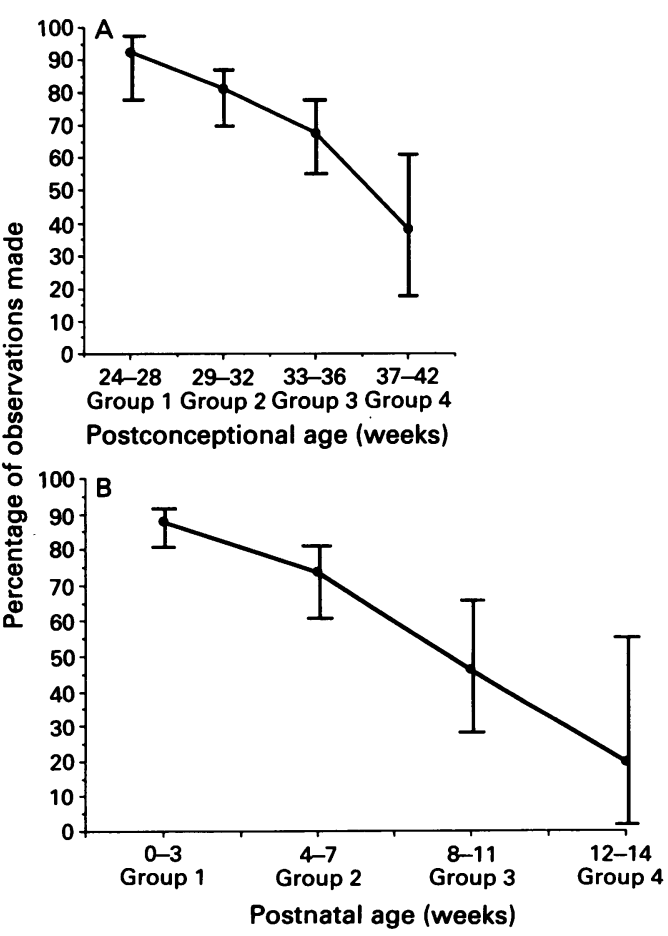

Figure 2 Presence of slow variability in $C B F V$ related to $(A)$ postconceptional age and $(B)$ postnatal age showing the percentage incidence and $95 \%$ confidence intervals. 
than nine recordings. Figures 3 and 4 show the epochs of CBFV recorded from one baby over 11 weeks, together with an example of such a regression analysis.

The pattern of evolution did not seem to relate to brain injury in the small group who sustained it except that, of the three who developed periventricular leucomalacia, one was the only baby who never demonstrated slow

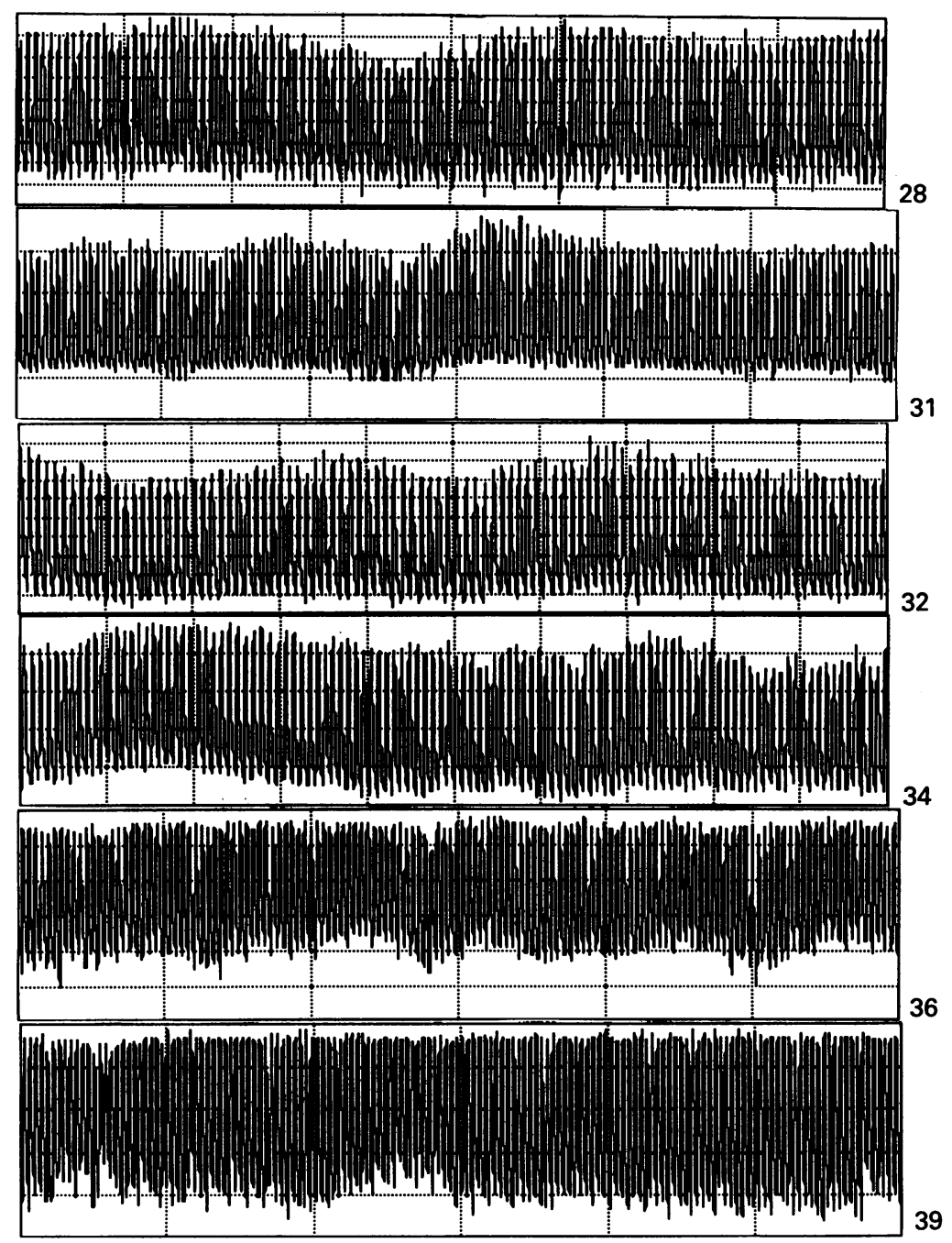

Figure 3 Evolution of slow variability in baby F from 28-39 weeks' postconceptional age.

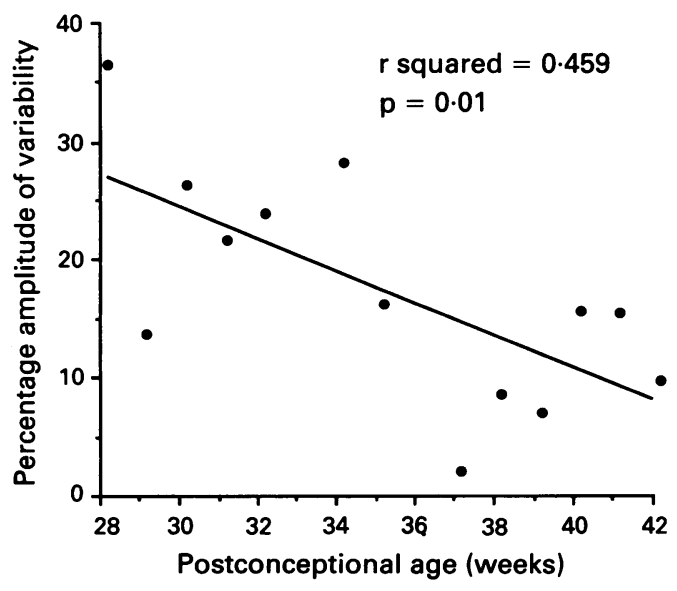

Figure 4 Regression analysis in baby $F$. variability; the others showed slow variability up to the time of discharge. In the six with periventricular haemorrhage no particular pattern could be seen.

The disappearance of slow variability in CBFV could not have been due to truncation of the peak systolic velocity; the automatic scaling within the software always allows the maximum velocity to be displayed.

Careful inspection reveals the appearance of slow variability in the diastolic velocity of cerebral blood flow. This was observed in 19 infants, generally after 31 weeks' postconceptional age.

\section{Discussion}

This longitudinal study confirms the presence of slow variability in the CBFV of babies in the frequency range 1.5 to 5 cycles/minute as observed by Anthony et $a l^{5}$; it has also shown postnatal evolution of the activity.

Slow variability occurred in the majority of very low birthweight infants in the first weeks of life, being recorded at least once in 29 of the 30 babies. It appeared to be independent of the presence of respiratory distress syndrome and of severity of illness as some of the infants required no respiratory assistance while others required early inotropic support and ventilatory assistance for up to 44 days. As this study included only babies still in the nursery at 4 weeks of age it excluded early neonatal deaths. Also, although the study infants were entered from a consecutive cohort of babies of birth weight $<1500 \mathrm{~g}$, those still in the nursery by $2-3$ months all had chronic lung disease so were a very selected group.

Perlman et al postulated that paralysis of sick preterm infants who had respiratory distress syndrome decreased beat to beat variability of CBFV and reduced the incidence of brain injury. ${ }^{15}$ In this study administration of pancuronium, fentanyl, or morphine in seven babies did not affect the presence of slow variability. The pattern of slow variability did not differ significantly between those without intracranial pathology and those with either periventricular haemorrhage or periventricular leucomalacia. The single baby who showed no slow variability had the most severe intracranial pathology of all babies studied. This would support the fact that slow variability is a normal phenomenon in newborn babies, absent only in cases of extreme pathology. Indeed absence of any variability in heart rate is an adverse prognostic indicator for respiratory distress syndrome. ${ }^{16}$ In severe respiratory distress syndrome, increased baseline heart rate and decreased variability may result from an increased concentration of circulating catecholamines which may represent abnormally high sympathetic activity. ${ }^{17}$

Since the original description of slow variability in blood pressure at a frequency independent of the respiratory frequency by Mayer, ${ }^{3}$ two other areas of cyclical activity have been recognised in both heart rate and blood pressure: a peak around $0.05 \mathrm{~Hz}$ is thought to be related to fluctuations in peripheral vascular tone as- 
sociated with thermoregulation and that around $0.12 \mathrm{~Hz}$ to the frequency response of the baroreceptor reflex. ${ }^{78}$ Work in adults and in animals has shown that variability is influenced by thermoregulation and by pharmacological manipulation of the parasympathetic and sympathetic nervous systems. The renin-angiotensin system has also been shown to play a significant part in short term cardiovascular regulation, and blocking this system increases the amplitude of very slow cycles $(0.04 \mathrm{~Hz})$ in dogs. ${ }^{18}$

High variability in the region of vasomotor influence $(0-0.1 \mathrm{~Hz})$ relative to that in the region of respiratory frequency $(0 \cdot 25-1.0 \mathrm{~Hz})$ is suggested to be a risk factor for sudden infant death syndrome and may represent slow maturation of the autonomic nervous system, with relative over-representation of the parasympathetic element. ${ }^{19}$ In the study group of premature babies the reduction in amplitude of slow variability may represent a maturation of the balance between the two components of the autonomic nervous system. The cycle length of slow variability was variable, suggesting that several low frequency components were represented but the recording time was limited to 1 minute by the computer software. Much longer recordings would be required to resolve the frequency of several very slow variabilities with any degree of accuracy.

The significance of slow cycling in the diastolic velocity which appeared later in gestation in just over half of the babies has yet to be explained. We have no evidence that slow variability is harmful; further work may clarify the significance of this exaggerated normal response.

We would like to thank the nursing staff of the special care baby unit, Rosie Maternity Hospital, Cambridge, and Francis Griffiths for help with software.

1 Traube L. Uber periodische Tatigkeitsanderungen des vaso- motorischen und Hemmings-Nervenzentrums. Centralblatt für die Medizinischen Wissenschaften 1865;56:880-5.

2 Hering E. Uber des Einfluss der Atmung auf den Kreislauf. Sitzungfberichte der Akademie der Wissenschaften in Wien 1869;60:829-36.

3 Mayer S. Studien zur physiologie des herzens und der Blutgefasse $V$. uber spontane Blutdruckschwankungen. Sitzungfberichte der Akademie der Wissenschaften in Wien Sitzungfberichte der Akademie der Wissenschaften in Wien
Mathematisch-Naturwissenschaftliche Klasse 1874;74: Mathematis

4 Guyton AC, Harris JW. Pressoreceptor-autonomic oscillation: a probable cause of vasomotor waves. Am $\mathcal{J}$ Physiol 1951;165:158-66.

5 Anthony MY, Evans DH, Leven MI. Cyclical variations in cerebral blood flow velocity. Arch Dis Child 1991;66:12-6.

6 Perlman JM, McMenamin JB, Volpe JJ. Fluctuating cerebral blood-flow velocity in respiratory-distress syndrome. N Engl f Med 1983;309:204-9.

7 Hyndman BW, Kitney RI, Sayers BM. Spontaneous rhythms in physiological control systems. Nature 1971;233:339-41.

8 Kitney RI. An analysis of the nonlinear behaviour of the human thermal vasomotor control system. $\mathcal{f}$ Theor Biol human thermal

9 Schechtman VL, Harper RM, Kluge KA. Development of heart rate variation over the first 6 months of life in normal infants. Pediatr Res 1989;26:343-6.

10 van Ravenswaaij-Arts CMA, Hopman JCW, Kollee LAA, Stoelinga GBA. The influence of physiological parameters on long term heart rate variability in healthy preterm infants. F Perinat Med 1990;18:131-8.

11 Ellingsen I, Hauge A, Nicolayson M, Thorensen $M$, Walloe $M$. Changes in human cerebral blood flow due to step changes in $\mathrm{PAO}_{2}$ and $\mathrm{PCO}_{2}$. Acta Physiol Scand 1987;129: 157-63.

12 Schlindwein FS, Evans DH. A real-time autoregressive spectrum analyser for Doppler ultrasound signals. Ultrasound Med Biol 1989;15:263-72.

13 Rennie JM, South M, Morley CJ. Cerebral blood flow velocity variability in infants receiving assisted ventilation. vech Dis Child 1987;62:1247-51.

14 Levene M, Dubowitz LMS, De Crespigny LCH. Classification of intraventricular haemorrhage. Lancet $1983 ; \mathrm{i}: 643$.

15 Perlman JM, Goodman S, Kreusser KL, Volpe JJ. Reduction in intraventricular haemorrhage by elimination of fluctuating cerebral blood flow velocity in preterm infants with respiratory distress syndrome. $N$ Engl f Med 1985;312: 1353-7.

16 Jenkins JG, Reid MMcC, McClure BG. Study of heart rate variability in sick newborn infants. Acta Paediatr Scand 1980;69:393-6.

17 Cheek DB, Malinek M, Fraillon JM. Plasma adrenaline and noradrenaline in the neonatal periòd, and infants with respiratory distress syndrome and placental insufficiency. Pediatrics 1963;31:374.

18 Akselrod S, Gordon D, Ubel FA, Shannon DC, Barger AC, Cohen RJ. Power spectrum analysis of heart rate fluctuation: a quantitative probe of beat-to-beat cardiovascular control. Science 1981;213:220-2.

19 Kitney RI. New findings in the analysis of heart rate variability in infants. Automedica 1984;5:289-310. 